\title{
Death from Hemophagocytic Lymphohistiocytosis Syndrome Due to Generalized Hemorrhage
}

\author{
Vahid Kaveh1 ${ }^{1}$ (D), Shahin Keshtkar Rajabi*2 ${ }^{(D)}$
}

1. Dept. of Medical Oncology and Hematology, Iran University Of Medical Sciences, Tehran, Iran

2. Dept. of Internal Medicine, Firoozgar Hospital, Iran University Of Medical Sciences, Tehran, Iran

\begin{tabular}{|c|c|}
\hline Article Info & ABSTRACT \\
\hline doi $10.30699 / j a m b s .28 .127 .119$ & \multirow{4}{*}{$\begin{array}{l}\text { Hemophagocytic lymphohistiocytosis (HLH) is the result of excessive cytokine } \\
\text { release, leading to over-response by immune cells, such as macrophages and T } \\
\text { lymphocytes. Here, we report a lethal case of HLH with a complete clinical course. } \\
\text { The patient was a } 45 \text {-year-old man with fever and chills since two months ago plus } \\
\text { splenomegaly, hepatomegaly, and pancytopenia. The Anti-HBc IgM was positive, } \\
\text { but the HBS antigen, anti-HCV, and HBS antibody were negative. Assessment for } \\
\text { cirrhosis was carried out by FibroScan, which showed F4 grade. The biopsy sampling } \\
\text { was impossible due to the low platelet count. During admission, generalized bleeding } \\
\text { was developed and led to alveolar hemorrhage, which subsequently resulted in the } \\
\text { patient's death. Liver necropsy certified the diagnosis of hemophagocytic syndrome. } \\
\text { Overall, according to the reported case in this paper, it should be remembered that } \\
\text { secondary HLH is an inflammatory phenomenon due to different conditions, such as } \\
\text { latent newly-developed infections. } \\
\text { Keywords: Diagnosis, Epidemiology, Hemophagocytic lymphohistiocytosis }\end{array}$} \\
\hline $\begin{array}{c}\text { Received: 2019/11/27; } \\
\text { Accepted: 2020/02/01; } \\
\text { Published Online: 01 Mar 2020; }\end{array}$ & \\
\hline \multirow[t]{3}{*}{$\begin{array}{l}\text { Use your device to scan and read the } \\
\text { article online }\end{array}$} & \\
\hline & \\
\hline & $\begin{array}{l}\text { Corresponding Information: } \\
\text { Shahin Keshtkar Rajabi: Dept. of Internal Medicine, Firoozgar Hospital, Iran University of Medical } \\
\text { Sciences, Tehran, Iran E-mail: } \underline{\text { sh_rajabi64@yahoo.com }}\end{array}$ \\
\hline (A) & ommercial 4.0 International License which permits \\
\hline
\end{tabular}

\section{Introduction}

Hemophagocytic lymphohistiocytosis (HLH) is the result of excessive cytokine release, leading to overresponse by immune cells, such as macrophages and $\mathrm{T}$ lymphocytes (1-3). Primary and secondary types are the HLH subtypes (4). Definite diagnosis is difficult due to various manifestations $(5,6)$. Severe hyperinflammation is developed by activated macrophages and T lymphocytes (6). Children are usually affected by primary HLH versus secondary HLH in adults (7). Due to life-threatening consequences, HLH should be diagnosed and treated promptly to attain the best prognosis, especially in secondary cases (8). The case fatality rate of $\mathrm{HLH}$ is approximately $10 \%$ and is usually due to generalized visceral bleeding (6). However, the mortality in some treatment-focused studies with a larger sample population ranged from $20 \%$ to $88 \%$ (9). Here, we report a lethal case of HLH with a complete clinical course.

\section{Case Report}

The patient was a 45-year-old male subject with fever and chills since two months ago without any specific circadian patterns. At initial admission, the body temperature was $38^{\circ} \mathrm{C}$ by oral measurement, and there was splenomegaly in clinical examination, which was detected by ultrasound as huge splenomegaly (diameter 84*205) plus hepatomegaly (span $155 \mathrm{~mm}$ ). Normal liver size is $10.5 \mathrm{~cm}$ in men and $7 \mathrm{~cm}$ in women, and the spleen's largest size is $12-14 \mathrm{~cm}$. Both kidneys had increased echo pattern with corticomedullary contrast, suggesting acute tubular necrosis. There was free fluid accumulation in pelvic and perihepatic regions. Also, there was a right-sided pleural effusion with a thickness of $188 \mathrm{~mm}$.

The Cytomegalovirus (CMV), Epstein-Barr virus (EBV), and Tuberculosis were assessed and ruled out. Lumbar puncture was not possible due to the low platelet count. The initial body temperature was $38^{\circ} \mathrm{C}$ and was up to $39^{\circ} \mathrm{C}$ during admission. Due to the inappropriate condition of the patient, the transfer was impossible. However, a computed tomography (CT) scan of various parts, presented by the patient, was total without any evidence of malignancy. Bone marrow aspiration and biopsy were normal, and macrophage was not seen. There were pancytopenia, high serum creatinine, and blood urea nitrogen, high (over 2000 $\mathrm{mg} / \mathrm{dl}$ ) lactate dehydrogenase (LDH), hyperuricemia, and abnormal liver enzyme, as well as bilirubin levels, in laboratory assessment.

The leukocyte count was as low as 1500 per $\mathrm{mm}^{3}$ at admission, and after one week reached 6800 per $\mathrm{mm}^{3}$. 
In protein electrophoresis, the albumin and alpha 1 proteins had low levels, but alpha 2 and gamma proteins had high levels. C-reactive protein (CRP) was positive, with a numerical amount of $15 \mathrm{mg} / \mathrm{L}$, and erythrocyte sedimentation rate (ESR) was high (41 $\mathrm{mm} / \mathrm{hr}$ ). The urinalysis showed $3+$ and $4+$ protein and blood in urine samples besides leukocyturia and mild bacteriuria. Venous blood gas analysis showed low Partial Pressure of Carbone Dioxide (PCO2), Base excess (BE), and Bicarbonate (HCO3) plus a high Partial Pressure of Oxygen (PO2) level. The antidouble stranded test (Anti-dsDNA), Liver kidney microsome antibodies (Anti-LKM), Anti-smooth muscle antibody test (ASMA), Antinuclear Antibodies (ANA), Antineutrophil cytoplasmic antibodies (PANCA, and C-ANCA) were all negative. The infectious causes for pancytopenia and huge splenomegaly, such as endocarditis, brucellosis, HIV infection, and leishmaniasis, were ruled out. The AntiHBC IgM was positive, but the HBS antigen, anti$\mathrm{HCV}$, and HBS antibody were negative. A high procalcitonin level $(7.9 \mathrm{ng} / \mathrm{ml})$ was also seen.

Assessment for cirrhosis was done by Liver Elastrography (FibroScan), which showed F4 grade and indicated the need for a liver biopsy by IQR/Med ratio of $20 \%$. However, the biopsy sampling was impossible due to the low platelet count (113000 and 56000 per $\mathrm{mm}^{3}$ at admission and after one week, respectively) and postponed till the normalization of the platelet count. The international normalized ratio (INR) was 1.2, and Partial Thromboplastin Time (PTT) was as long as $60 \mathrm{~s}$. One of the proposed differential diagnoses was a hemophagocytic syndrome. Accordingly, the ferritin and triglyceride levels were assessed. Also, the bone marrow biopsy was carried out to assess the macrophage aggregation, but it was negative. Dexamethasone was prescribed for the patient because of the high suspicion of hemophagocytic syndrome.

During admission, generalized bleeding was developed and led to alveolar hemorrhage, which subsequently resulted in the patient's death. Liver necropsy showed that there were many macrophages, and the diagnosis was by standard clinical criteria by the American Pathology Association (Figure 1). Regarding high fever, splenomegaly, pancytopenia, high ferritin, and high number of macrophages in necropsy, the patient had five out of eight criteria, and it was established by a hematologist.

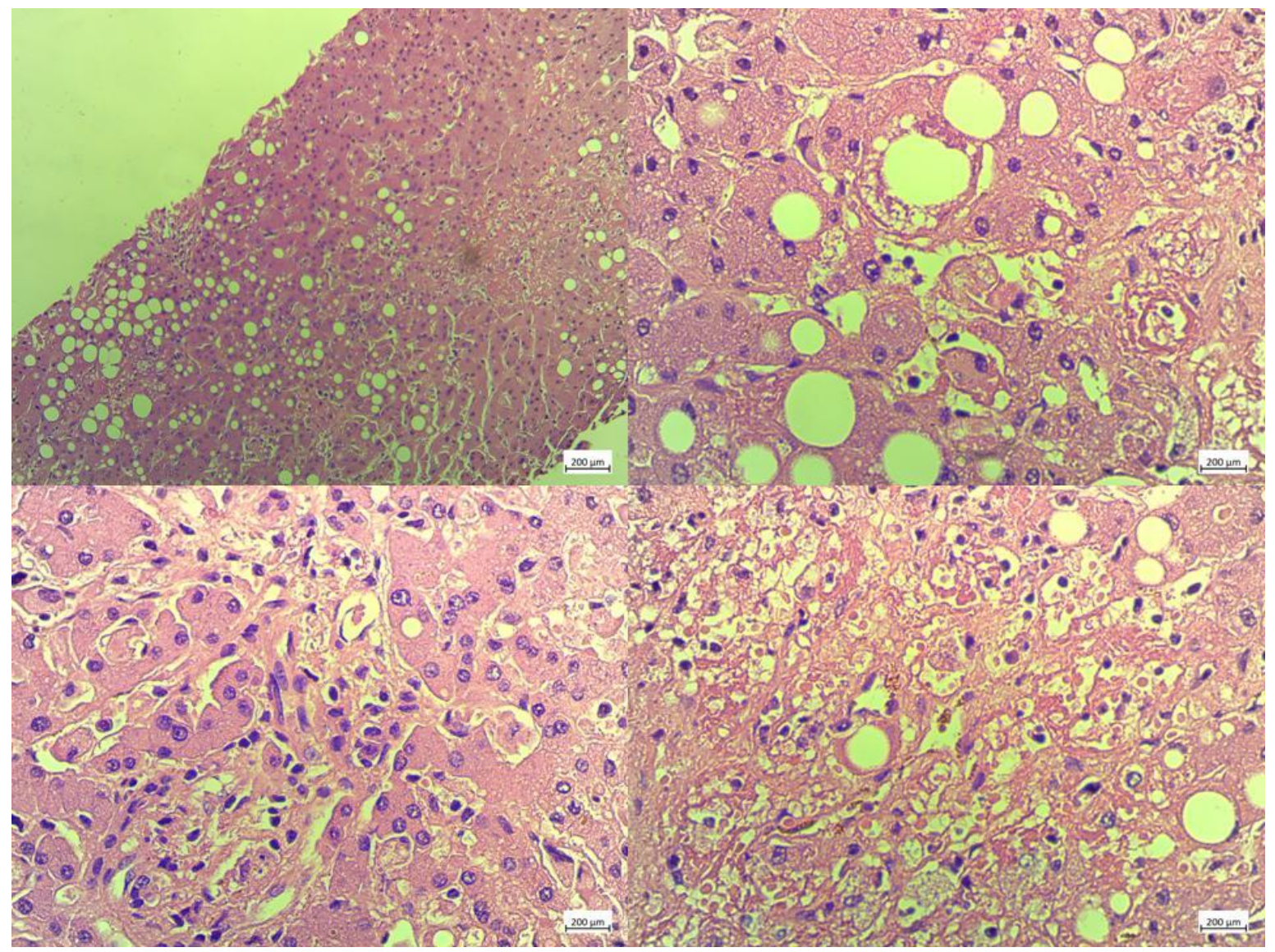

Figure 1. Histopathological results of liver necropsy; there are many macrophages in the tissue 
Table 1. The classification of superficial palmar arches according to Coleman and Anson (from references 9)

\begin{tabular}{|ccc|}
\hline Test & Amount & NL \\
\hline ANA & $1 / 40$ & Up to $1 / 80$ \\
\hline ESR & 41 & $<15$ \\
CRP & 15 & $<3$ \\
\hline Anti-DS DNA & 2 & $<30$ \\
\hline ASMA & - & - \\
\hline P-ANCA & 0.3 & $<5$ \\
\hline C-ANCA & 1.2 & $<5$ \\
\hline Wright & $1 / 20$ & $>1 / 80$ \\
\hline BUN & 75 & $7-20$ \\
\hline Cr & 3.5 & $0.8-1.4$ \\
\hline Uric acid & 6 & $3.4-7$ \\
\hline LDH & 2400 & $140-280$ \\
\hline AST & 250 & $10-40$ \\
ALT & 362 & $7-56$ \\
\hline ALP & 368 & $20-140$ \\
\hline Bil T & 4.6 & $0.2-1.2$ \\
\hline Bil D & 2.8 & \\
\hline INR & 1.2 & $<1.1$ \\
\hline PTT & 60 & $40-50$ \\
\hline Ferritin & 680 & $12-300$ \\
\hline TG & 183 & $<150$ \\
Procalcitonin & 7.9 & $0.1-0.44$ \\
\hline & & \\
\hline & & \\
\hline
\end{tabular}

\section{Discussion}

HLH is a potentially life-threatening condition with triggering pre-inflammatory factors. The middle-aged male patient, reported in this paper, had a two-month history of fever and chills and nearly the ten-day course of final life process from the hospital admission to final death. Dhawale et al. (10) reported an 18-year-old Indian male patient presenting with a two-month history of fever, generalized weakness, and weight loss, as seen in our patient. The diagnosed condition was established by the HLH-2004 criteria in their study. In their report, the patient was survived after that the pleural fluid was assessed microbiologically, and the presence of mycobacterium tuberculosis was demonstrated and led to standard therapy.

Our patient had a positive result for anti-HBc IgM, suggesting a possible etiological role for hepatitis B infection. However, the only used treatment was dexamethasone that showed no life-saving effect and possibly led to further provocation of disease. Regarding high suspicion, high dose dexamethasone with a dose of $40 \mathrm{mg} /$ day was initiated. Because of no definite diagnosis and incomplete criteria, as well as no satisfaction among the patient's relatives, chemotherapy was not initiated.

Diagnostic criteria for HLH should minimally include the presence of five out of the eight criteria, including fever, splenomegaly, cytopenia (anemia, thrombocytopenia, and neutropenia), hypertriglyceridemia or hypofibrinogenemia, hemophagocytosis in body organs without malignancy, low activity in natural killer cells, increased ferritin, and high CD25 (11-13). However, less than five criteria were found in our study that led to delayed diagnosis despite high suspicion.

Thomas et al. (14) reported five HLH cases with the expiration of four patients. One of the patients was died due to generalized hemorrhage, such as our reported case. The background conditions in their patients were immunological, infectious, and malignancies, showing the importance of the completion of diagnostic approaches in our study to detect the definite primary etiology. However, the recognition of background etiology would result in a further chance of treatment and life-saving attempts.

Furthermore, Ferreira et al. (15) reported seven cases of HLH that led to two fatal cases. Also, the primary infections were Epstein-Barr virus, cytomegalovirus, and leishmaniasis in three, one, and two cases, respectively, with one idiopathic case. Aleem et al. (16) reported a patient that found to have evidence of chronic hepatitis $\mathrm{B}$ infection according to the serological tests and liver biopsy. 
However, the patient in our study had acute hepatitis $B$ infection according to positive IgM levels of anti$\mathrm{HBc}$ antibody. Also, Halfon et al. (17) reported a case of HLH due to acute Cytomegalovirus and Hepatitis-B Virus sexual co-infection, but the reported case in our study had no clear route of acquisition of hepatitis B infection. In Iran, a study by Shamsian et al. (18) reported six cases of primary HLH and their outcome from a single tertiary-care center in Tehran.

\section{Conclusion}

Totally, according to the reported case in this paper, it is concluded that secondary HLH is an inflammatory phenomenon due to different conditions, such as latent newly-developed infections. The patients would have a better prognosis if diagnosed and treated promptly with the goal-oriented treatment of background disease.

\section{Acknowledgment}

The authors thank all those who helped them in writing this paper.

\section{Conflict of Interest}

The authors declared that there is no conflict of interest regarding the publication of this case report.

\section{References}

1. George MR. Hemophagocytic lymphohistiocytosis: review of etiologies and management. J Blood Med. 2014;5:69-86. [DOI:10.2147/JBM.S46255]

2. Janka GE, Lehmberg K. Hemophagocytic lymphohistiocytosis: pathogenesis and treatment. Hematology Am Soc Hematol Educ Program. 2013;2013:605-11. [DOI:10.1182/asheducation2013.1.605]

3. Fisman DN. Hemophagocytic syndromes and infection. Emerg Infect Dis. 2000;6(6):601-8. [DOI:10.3201/eid0606.000608]

4. Grzybowski B, Vishwanath VA. Hemophagocytic Lymphohistiocytosis: A diagnostic conundrum. J Pediatr Neurosci. 2017;12(1):55-60. [DOI:10.4103/jpn.JPN_140_16]

5. Filipovich AH. Hemophagocytic lymphohistiocytosis (HLH) and related disorders. Hematology Am Soc Hematol Educ Program. 2009:127-31. [DOI:10.1182/asheducation2009.1.127]

6. Morimoto A, Nakazawa Y, Ishii E. Hemophagocytic lymphohistiocytosis: Pathogenesis, diagnosis, and management. Pediatr Int. 2016;58(9):817-25. [DOI:10.1111/ped.13064]
7. Shah AR, Muzzafar T, Assi R, et al. Hemophagocytic lymphohistiocytosis in adults: An under recognized entity. BBA Clin. 2016;7:36-40. [DOI:10.1016/j.bbacli.2016.12.002]

8. Bhatt NS, Oshrine B, An Talano J. Hemophagocytic lymphohistiocytosis in adults. Leuk Lymphoma. 2018:1-10. [DOI:10.1080/10428194.2018.1482543]

9. Hayden A, Park S, Giustini D, Lee AY, Chen LY. Hemophagocytic syndromes (HPSs) including hemophagocytic lymphohistiocytosis (HLH) in adults: A systematic scoping review. Blood Rev. 2016;30(6):411-20.

[DOI:10.1016/j.blre.2016.05.001]

10.Dhawale MS, Joshi AR, Bhatkule MA, Kumbhakarna NR, Bindu RS. Hemophagocytic syndrome. Indian J Hematol Blood Transfus. 2014;30(Suppl 1):9-11. [DOI:10.1007/s12288-012$\underline{0217-0]}$

11. Chute DJ, Rawley J, Cox J, Bready RJ. Sudden unexpected death due to hemophagocytic lymphohistiocytosis syndrome. J Forensic Sci. 2013;58(4):1080-4. [DOI:10.1111/15564029.12131]

12.Ullah W, Abdullah HM, Qadir S, Shahzad MA. Haemophagocytic lymphohistiocytosis (HLH): a rare but potentially fatal association with Plasmodium vivax malaria. BMJ Case Rep. 2016;2016. [DOI:10.1136/bcr-2016-215366]

13.Zhang Z, Wang J, Ji B, et al. Clinical presentation of hemophagocytic lymphohistiocytosis in adults is less typical than in children. Clinics (Sao Paulo). 2016;71(4):205-9. [DOI:10.6061/clinics/2016(04)05]

14. Thomas D, Shah N, Patel H, Pandya T, Gauchan D, Maroules M. Hemophagocytic Lymphohistiocytosis: A series of five clinical cases in adult patients at a single institution with a review of the literature. N Am J Med Sci. 2015;7(9):41520. [DOI:10.4103/1947-2714.166225]

15.Ferreira DG, do Val Rezende P, Murao M, Viana MB, de Oliveira BM. Hemophagocytic lymphohistiocytosis: a case series of a Brazilian institution. Rev Bras Hematol Hemoter. 2014;36(6):437-41. [DOI:10.1016/j.bjhh.2014.07.003]

16. Aleem A, Al Amoudi S, Al-Mashhadani S, Siddiqui N. Haemophagocytic syndrome associated with hepatitis-B virus infection responding to etoposide. Clin Lab Haematol. 2005;27(6):395-8. [DOI:10.1111/j.1365-2257.2005.00728.x]

17.Halfon P, Retornaz F, Mathieu D, Helbert T, Philibert P, Pégliasco H. Virus-associated hemophagocytic syndrome related to acute CMV and HBV sexual co-infection: a case report. J Clin 
Virol. 2009;46(2):189-91.

[DOI:10.1016/j.jcv.2009.07.001]

18. Shamsian BS, Rezaei N, Alavi S, et al. Primary hemophagocytic lymphohistiocytosis in Iran: report

How to Cite This Article:

Kaveh V, Keshtkar Rajabi S. Death from Hemophagocytic Lymphohistiocytosis Syndrome Due to Generalized Hemorrhage. J Adv Med Biomed Res. 2020; 28 (127) :119-123

\section{Download citation:}

$\underline{\text { BibTeX }}|\underline{\text { RIS }}| \underline{\text { EndNote }}|\underline{\text { Medlars }}| \underline{\text { ProCite }} \mid$ Reference Manager $\mid \underline{\text { RefWorks }}$

\section{Send citation to:}

Mendeley 2 Zotero (i) RefWorks RefWorks from a single referral center. Pediatr Hematol Oncol. 2012;29(3):215-9. [DOI: $10.3109 / 08880018.2012 .657338]$ 